\title{
A criança com síndrome de Down: o sentido da inclusão no contexto da exclusão
}

\author{
Ana Paula da Silva Azevedo* \\ Anderléia Sotoriva Damke**
}

\section{Resumo}

O presente estudo tem por finalidade conhecer o processo de inclusão escolar de uma aluna do $2^{\circ}$ ano do ensino fundamental com Síndrome de Down. Enfatizamos o objetivo da escola inclusiva, cuja intenção não é igualar a criança aos colegas, mas fazer com que aprenda dentro de suas possibilidades. Para que isso ocorra, é crucial que as crianças com deficiência tenham o apoio de que precisam, o respeito às suas limitaçôes e a oferta de oportunidades adequadas, levando em consideração as diferenças individuais, com atividades diversificadas e motivadoras. A pesquisa, de natureza qualitativa, buscou, por meio da observação participante do cotidiano da criança Down e de questionários abertos aplicados com profissionais da educação, como a coordenadora, a professora regente e a auxiliar itinerante, apreender o processo de inclusão em uma escola pública do estado de Mato Grosso do Sul. A análise dos dados sistematizados e o aporte teórico sinalizaram que as escolas inclusivas devem reconhecer os fatores que influenciam o processo de inclusão e dar uma resposta a cada um deles, assegurando educação por meio de um currículo apropriado, modificaçóes organizacionais, estratégias de ensino, uso apropriado de recursos e parcerias. As evidências levantadas nas observaçóes, comparadas aos relatos, sustentam a ideia de que o apoio oferecido pela escola onde a pesquisa foi conduzida é insuficiente para uma inclusão bem-sucedida. O estudo realizado favoreceu a reflexão de que as escolas prescindem da sistematização dos seu tempos, espaços e relaçôes, para que se efetive uma inclusão que supere o distanciamento entre o discurso e a prática.

Palavras-chave: Síndrome de Down; Educação inclusiva; Ensino regular.

* Pedagoga pela Universidade Federal de Mato Grosso do Sul, Campo Grande, Mato Grosso do Sul, Brasil.

** Professora da Universidade Tecnológica Federal do Paraná, Curitiba, Paraná, Brasil. 


\section{Child with Down syndrome: the meaning of inclusion in the context of exclusion}

\section{Abstract}

This study aims to understand the process of school inclusion of a sophomore elementary school with Down syndrome. We emphasize the goal of inclusive school, whose intention is not match the child to colleagues, but to make learn within their means. For this to happen, it is crucial that children with disabilities have the support they need, respect for their limitations and the provision of adequate opportunities, taking into account individual differences, diverse and motivating activities. The research, qualitative, sought, through everyday participant observation of the child down and open questionnaires with education professionals, as the coordinator, the regent teacher and traveling helper, grasp the process of inclusion in a public school the state of Mato Grosso do Sul. the analysis of systematic data and signaled theoretical framework that inclusive schools should recognize the factors that influence the process of inclusion and give an answer to each of them, ensuring education through an appropriate curriculum, organizational, teaching strategies, appropriate use of resources and partnerships. The evidence raised in the observations, compared to reports, support the idea that the support offered by the school where the study was conducted is insufficient for successful inclusion. The study favored the reflection that dispenses schools systematization of its time, space and relationships, to be made effective an inclusion that overcomes the gap between theory and practice.

Keywords: Down syndrome; Inclusive education; Regular education.

\section{Introdução}

Atualmente, o meio educacional é cenário de várias discussôes. Dentre as mais evidentes, está a questão da inclusão de pessoas com necessidades especiais, como as crianças com Síndrome de Down (SD). Tais discussóes raramente se efetivam em açóes concretas e, geralmente, pouco avançam para melhorar a qualidade de ensino. O conhecimento mais profundo sobre as crianças com Síndrome de Down e suas habilidades e limitaçóes é de extrema relevância para familiares e professores, para que estimulem adequadamente a criança, proporcionando-lhe um desenvolvimento dentro das suas capacidades.

O tema geral da inclusão é um assunto complexo, complexidade que se intensifica quando se trata de pessoas com algum tipo de deficiência, inclusive a Síndrome de Down. Atualmente, falar de inclusão é comum, mas é preciso que haja mais do que meros enunciados vazios. É imprescindível, antes de tudo, uma mudança de pensamento da sociedade em relaçấo a esses debates. A comunidade escolar necessita de uma preparaçáo para que a inclusão deixe de existir só no discurso e realmente se traduza em açôes. 
Tendo em vista a inclusão, esta pesquisa busca analisar a inclusão escolar de uma aluna com Síndrome de Down, do $2^{\circ}$ ano do ensino fundamental de uma escola pública de ensino regular do estado de Mato Grosso do Sul. É oportuno salientar que a escola foi escolhida por empreender um trabalho de inclusão com 12 casos de alunos com deficiências, como física, baixa visão, cegueira e surdez. O objetivo é destacar, por meio da observação participante com a duração de dois meses, o processo de inclusão da aluna Down, seu desenvolvimento e aprendizagem e, assim, distinguir as maneiras e as estratégias que viabilizam o processo de inclusão. Atentar para essas maneiras e estratégias significa descrever a proposta de inclusão do Projeto Político-Pedagógico da escola e investigar a atuação docente no trabalho de inclusão dessa criança, ou seja, saber se a escola está preparada para atender adequadamente a essa criança, conforme as suas necessidades.

Para a efetivação da pesquisa, realizada em 2012, conduzimos uma revisão bibliográfica, além da adoção da abordagem qualitativa para a obtenção de dados. $\mathrm{Na}$ investigação, recorremos às técnicas de questionário e de análise documental (Projeto Político-Pedagógico), a fim de auxiliar no levantamento de aspectos que possibilitassem, a partir das respostas dos participantes, verificar como tem sido a organizaçáo pedagógica da escola frente à inclusão da aluna com Síndrome de Down. Durante dois meses, observamos, com o objetivo de conhecer o processo de inclusão, as metodologias utilizadas, para complementar e enriquecer as informaçóes que seriam coletadas por meio dos questionários abertos aplicados aos profissionais da educação, nesse caso, a coordenadora, a professora regente e a auxiliar itinerante.

A Síndrome de Down tornou-se objeto de estudo de uma das professoras a partir do nascimento do seu do filho Lucas, que apresenta a Síndrome. Pais de crianças com a Síndrome se defrontam com alguns dilemas quando seus filhos atingem a idade de frequentar o ensino fundamental e se questionam se devem ou não colocá-los numa escola de ensino regular. Quando os pais são professores, usualmente se aprofunda o questionamento sobre as condiçôes apropriadas para a sua permanência e aprendizagem. É evidente a preocupação dos pais com os aspectos educacionais de seus filhos.

Ao mesmo tempo em que se proclama a inclusão pelos profissionais em geral, os pais enfrentam dificuldades para que seus filhos sejam aceitos nas escolas e 'trabalhados' de um modo adequado, que atenda às suas necessidades educacionais, uma vez que a igualdade mascara o preconceito. Compreendemos a inclusão como a observação dos princípios que atendem à aceitação das diferenças individuais e à aprendizagem, por meio da colaboração e das relaçôes de convivência. A partir de Mantoan (2003), reiteramos que a inclusão implica uma mudança de paradigma educacional, uma vez que exige uma reorganização das práticas escolares, como planejamentos, currículo, avaliação e gestão do processo avaliativo. As crianças com Síndrome de Down carecem de uma ação educativa apropriada para o atendimento das suas necessidades especiais. 


\section{processo de inclusão da criança com síndrome de Down}

É imperativo, então, um conhecimento mais profundo sobre as crianças com a Síndrome de Down. Para desenvolver uma ação pedagógica que promova a sua inclusão escolar, antes de tudo é preciso verificar as suas características específicas. $\mathrm{Na}$ chamada "Conferência Mundial sobre Necessidades Educativas Especiais", em Salamanca (Espanha), em 1994, firmou-se um compromisso com a educação para todos. Foi acordada a inclusão de crianças, de jovens e de adultos com necessidades educativas especiais no sistema comum de educação. Segundo a Declaração de Salamanca, a escola deve incluir todos, evidenciando-se a diversidade, e precisa atender às necessidades de cada um, promovendo a sua aprendizagem (BRASIL, 1994).

No cenário do processo da inclusão depreendemos, como defende Imbernón (2000), que a igualdade de oportunidades e a equidade são os desafios mais significativos para a verdadeira inclusão. Assim, como política pública, a escolarização tem que oferecer as mesmas oportunidades de formação para todos, ou seja, deve adaptarse às diferenças, às características específicas de seus alunos, notadamente às daqueles com deficiências, para respeitar as diferenças e tornar-se mais justa.

De acordo com Schwartzman (2007) a Síndrome de Down não é uma doença, mas uma alteração genética natural. O mecanismo biológico que aciona a Síndrome é ainda desconhecido. Durante a gestação, as células do embrião são formadas com 47 cromossomos em vez dos 46 que se formam normalmente. O autor lembra que, antigamente, a pessoa com SD era rotulada como deficiente mental. $\mathrm{O}$ autor ainda explica que, em 1866, o cientista John Langdon Down escreveu um artigo em que classificou as pessoas na condição da síndrome como mongoloides e idiotas, como seres inferiores. Somente em 1959 o Dr. Jerome Lejeune descobriu a presença de um cromossomo extra, ou seja, a presença de um erro genético por parte da natureza. Esse cromossomo extra produz, portanto, diferenças genéticas em relação às outras pessoas. O Dr. Jerome Lejeune denominou a sua descoberta de 'Síndrome de Down' em homenagem a John Langdon Down.

Nesse contexto, Schwartzman (2007) descreve que as características e a etiologia da Síndrome de Down são muitas, e algumas delas não influenciam no desenvolvimento da criança. Acontece, contudo, que cada característica, de forma peculiar, marca diferenças físicas, como: (i) perfil achatado; (ii) nariz pequeno e o osso nasal geralmente achatado, sendo, em algumas crianças, a passagem nasal mais estreita; (iii) hipoplasia (diminuiçấo da atividade dos 27 tecidos da face); (iv) boca e dentes pequenos, de forma que a língua pode projetar-se para fora; (v) língua hipotônica (com a diminuição do tônus muscular, a língua pode ficar com estrias); e (vi) o céu da boca ou palato é estreito.

Além das características citadas para os afetados pela SD: (i) seus cabelos são finos e lisos; (ii) possuem pregas epicânticas ou pregas palpebronasais que se estendem do nariz até a parte interna da sobrancelha, cobrindo o canto interno do olho; (iii) as orelhas são pequenas, com baixa implantação; assim, a borda superior da orelha, 
geralmente, é dobrada e os canais do ouvido estreitos; (iv) prega palmar transversal única; (v) as mãos e os pés tendem a ser pequenos e grossos e existe uma distância entre os dedos dos pés, um espaço maior entre o dedão e o segundo dedo; (vi) nas mãos, vê-se o encurvamento dos quintos dígitos; e (vii) a parte posterior da cabeça é levemente achatada, o que é chamado de braquicefalia. Enfim, a SD pode se manifestar em qualquer raça, sejam povos negros, amarelos ou brancos.

Quanto às características dos indivíduos com SD, Schwartzman (2007) realça que geralmente tendem para comportamentos calmos, afetivos, bem-humorados e com alguns prejuízos cognitivos, mas que, em alguns casos, há variações bastante distintas. Assim, a personalidade varia muito de indivíduo para indivíduo, com registros de alguns distúrbios de comportamento. A atitude de um sujeito com Síndrome de Down pode depender do seu potencial genético e das características culturais do meio em que convive.

Melero (1999) defende que para favorecer a educação da criança com SD, é determinante o trabalho com os processos cognitivos: percepção, atenção, memória e organização de itinerários mentais, uma vez que a inteligência não se define, constróise. A genética representa apenas uma possibilidade; as competências cognitivas são adquiridas ao longo do processo de desenvolvimento, a partir dos estímulos.

\section{A escola e a inclusão}

O papel principal da escola é criar condiçóes para que a maioria dos alunos tenha sucesso na aprendizagem, independentemente das suas diferenças, quer físicas, culturais, sociais, cognitivas ou outras. Concebemos, então, que a filosofia de uma sociedade inclusiva e, consequentemente, da escola inclusiva, é que as pessoas com deficiências devem ter as suas necessidades especiais atendidas.

Nessa direção, Mantoan (2003) nos faz repensar sobre as formas de exclusão escolar que se manifestam de diversas e perversas maneiras, dentre elas, de trabalhar a igualdade e a homogeneidade. Para a autora, é imperativo repensar a inclusão no cenário em que nem todas as diferenças inferiorizam as pessoas e, ainda, que o direito de sermos diferentes e iguais: diferentes, quando a igualdade nos descaracteriza; iguais, quando a diferença nos inferioriza. Portanto, o processo de inclusão, que é o inverso de exclusão, subsidia a reorganizaçáo dos tempos, dos espaços e das relaçóes no cotidiano escolar.

Schwartzman (2007), sob a mesma perspectiva, advoga a ideia de que a educação da criança é uma atividade complexa, pois exige adaptaçôes de ordem curricular que requerem cuidadoso acompanhamento dos educadores e dos pais. Como a criança com Síndrome de Down apresenta algumas limitaçóes, o trabalho pedagógico deve, primordialmente, respeitar o seu ritmo e assegurar-lhe estimulaçáo adequada para o desenvolvimento de suas habilidades.

Vieira e Pereira (2003) propóem que o currículo escolar para alunos com deficiência deve perseguir os seguintes objetivos: (i) reforço da formação geral; (ii) desenvolvimento de aptidóes genéricas para a vida ativa e hábitos de trabalho; (iii) o 
máximo de desenvolvimento pessoal nas vertentes individual e social, respeitando a diversidade; (iv) cuidado com os aspectos físicos, afetivos e intelectuais de forma global, em cada momento evolutivo e em função dos diferentes contextos da vivência. Tais adaptaçôes devem visar às necessidades do aluno, podendo ser aplicadas à medida que são identificadas. As adaptaçóes curriculares em funçáo da inclusáo ficam por conta de cada escola.

O artigo 12 da LDB no 9394/96 indica que as instituiçóes, respeitando as normas comuns e as do seu sistema de ensino, têm a responsabilidade de elaborar e executar sua proposta pedagógica. Esse documento precisa estar voltado para os direitos, os interesses e as necessidades de todos os envolvidos no processo educacional.

Além disso, segundo Libâneo et al. (2005, p. 345), “O Projeto Político Pedagógico é um documento que propóe uma direção política e pedagógica para o trabalho escolar, formula metas, prevê açóes, institui procedimentos e instrumentos de ação". Esse documento é, portanto, extremamente valioso, justamente por ser considerado um guia para as açôes da escola. Pode ser alterado diante das situaçóes que emergem no cotidiano escolar, inserindo adequadamente os alunos inclusos.

O Projeto Político-Pedagógico reflete a identidade da instituição e a direção na qual vai caminhar, com propostas que privilegiem todos os que convivem nesse ambiente, no comprometimento e na intencionalidade de se construírem cidadáos participativos, críticos e criativos. Tal documento subsidia o processo de inclusão, sinalizando que não é o aluno que precisa mudar: a escola pode se reordenar, no seu tempo, no seu espaço e nas suas relaçóes, para receber os alunos com suas necessidades e com suas diferenças, concretizando a verdadeira inclusão.

\section{Procedimentos metodológicos}

Nesta seção, introduzimos a pesquisa de campo efetuada em 2012, cujo objetivo foi conhecer o processo de inclusão de uma aluna com Síndrome de Down. Para a realização da pesquisa, adotamos a abordagem qualitativa, por ser mais apropriada para assimilar a natureza de um fenômeno social complexo e único, como o da inclusão escolar. De acordo com Chizzotti (2005), a pesquisa qualitativa vai ao encontro do interesse por um relacionamento dinâmico entre o mundo real e o sujeito, uma interdependência viva entre o sujeito e o objeto.

A escola selecionada para a pesquisa é pública, localiza-se no estado de Mato Grosso do Sul, oferece o ensino fundamental e já desenvolve um trabalho com 12 crianças com necessidades educacionais: necessidade físicas, surdez, cegueira, baixa visão e Down. Atende a 887 alunos, no total. Os participantes da pesquisa incluem profissionais da educaçáo vinculados ao trabalho empreendido com uma aluna de nove anos com Síndrome de Down, que cursa o $2^{\circ}$ ano do ensino fundamental.

Na coleta de dados, procedemos à observação participante da aluna Down no contexto escolar e aos questionários abertos, aplicados com a coordenadora pedagógica, a professora regente e a professora auxiliar itinerante. Em conformidade com o que preconizam Alves-Mazzotti e Gewandsznajder (1999), a técnica da observaçáo 
participante não estruturada centraliza-se nos comportamentos que são testemunhados e descritos da forma como ocorrem, na tentativa de apreender o que está acontecendo naquele determinado momento.

Durante a fase de observação, que durou aproximadamente dois meses, objetivamos apreender o processo de inclusão escolar da aluna Down. Aplicamos os questionários com as pessoas diretamente envolvidas no processo inclusivo: dois questionários abertos, um contendo oito itens abordando a proposta da escola, respondido pela coordenadora pedagógica, e o outro contendo 18 questóes para as professoras regente e auxiliar, a fim de relatar a aprendizagem e a compreensão das práticas pedagógicas sob o olhar da inclusão.

A identificação pessoal dos sujeitos participantes da pesquisa foi preservada. São nomeadas desta forma: AI (aluna inclusa), CP (coordenadora pedagógica), PR (professora regente) e PI (professora itinerante). A CP tem formação em Pedagogia, está cursando Pós-graduação em Gestão Escolar, trabalha na rede municipal no estado de Mato Grosso do Sul há, aproximadamente, 20 anos. A PR tem formação em Pedagogia e Pós-graduação em Educação Infantil e Anos Iniciais. É professora há cerca de cinco anos, também na rede municipal. A PI é uma estagiária que está cursando Pedagogia. Atua como contratada também na rede municipal há, aproximadamente, dois anos.

\section{Discussão e análise: a aluna Down e os profissionais da educação}

Para entender melhor o processo de inclusão, realçamos aqui as observações feitas com a aluna na sala de aula do $2^{\circ}$ ano do ensino fundamental. A turma tem 25 alunos, o número máximo que a legislaçáo recomenda, quando da presença de algum aluno com deficiência. A AI apresenta Síndrome de Down, tem nove anos, é uma menina alegre, gosta muito de dançar e demonstra muito carinho com as pessoas ao seu redor. Seu relacionamento com os colegas é bem harmonioso, inclusive nas brincadeiras, em momentos de recreação.

No processo de ensino e aprendizagem, a AI tinha uma auxiliar para o desenvolvimento dos exercícios. Mesmo assim, não conseguia cumprir tudo o que era proposto pela professora. Durante a produção das atividades escritas sugeridas pela professora regente no quadro, registramos reaçóes de cansaço e de desmotivação. Em alguns momentos, chegava a se debruçar em cima da mesa. Quando demonstrava esse tipo de atitude, a itinerante a incentivava, ditando letra por letra. A aluna sabia todas as letras do alfabeto, só que ainda não conseguia formar palavras, apenas o seu nome. Ela demonstrava mais interesse em atividades de colorir - a sua coordenaçáo motora era bem desenvolvida; fazia tudo com muito capricho e zelo.

Durante a observação, ficou nítido que o ambiente escolar não atendia à flexibilização curricular, uma vez que os conteúdos trabalhados em sala eram os mesmos para a aluna Down, ou seja, não existia algo diferenciado para atender às suas necessidades de aprendizagem. No decorrer das observaçóes, não constatamos nenhum diálogo da professora com a itinerante, em relação às dificuldades da aluna. Essa 
atitude do professor regente faz uma grande diferença no aprendizado durante o desenvolvimento das atividades na aula. Tais situaçôes evidenciam a preocupação ao mencionarmos a inclusão no contexto da exclusão, uma vez que a escola real, às vezes, propicia a integraçáo, e não a inclusão, que deveria ser vivenciada por meio da articulação, principalmente no cenário pedagógico.

$\mathrm{Na}$ aplicação do questionário, perguntamos sobre a aceitação da matrícula da aluna com Síndrome de Down. De acordo com a CP: "A comunidade escolar não teve nenhum receio em aceitar a matrícula da aluna. A única preocupação era incluir essa criança em uma turma que a acolhesse bem". E ao ser indagada sobre o que a escola tem feito para melhorar o atendimento à aluna com Síndrome de Down, a CP informou que "[...] a escola oferece o professor itinerante, com objetivo de atendê-la individualmente, e procura trabalhar com material diferenciado". O relato da CP nos reporta à ideia de Mantoan (2003), para quem a inclusão é inserir uma pessoa na sua comunidade e nos ambientes destinados à sua educação e, além disso, implica conceber as pessoas como seres únicos, diferentes uns dos outros; o princípio da escola inclusiva é que todas as crianças aprendam juntas, independentemente das diferenças e tenham a mesma oportunidade de acesso, de permanência e de aproveitamento na escola.

Ao questionarmos a $\mathrm{CP}$ sobre os recursos que a escola disponibiliza à professora e à aluna, ela relatou: "O apoio oferecido ainda não é o suficiente, acredito que ainda tem muito a oferecer a este aluno. $\mathrm{O}$ trabalho na instituiçáo é feito em parceria com a Gerência Municipal de Educação do município, oferecendo também sala de recursos e atividades físicas específicas, fora do seu ambiente escolar". A esse respeito, Mantoan (2003) defende que a inclusão não prevê a utilização de práticas pedagógicas específicas para determinadas deficiências, o que leva o professor a explorar as possibilidades de cada um. Entretanto, não podemos nos esquecer da primordialidade de planejar as aulas levando em conta a inclusão e de atender às condiçôes específicas dos alunos. Quando igualamos os alunos, mascaramos a discriminação e o preconceito para com eles.

No contexto da inclusão da aluna com Síndrome de Down, a CP narrou que a comunidade escolar buscou mais informaçóes sobre a Síndrome, mas acredita que ainda não é o ideal, pois somente a PR e a turma foram informadas sobre o assunto. De acordo com os dados coletados, por meio da análise documental do Projeto Político-Pedagógico (PPP) referente ao ano de 2008, apresentado pela CP, vemos que a escola dispõe de projeto, mas ainda não incorpora o processo de inclusão.

Encontramos a seguinte explicação no documento do PPP da instituição: "[...] a necessidade de fortalecimento no atendimento ao aluno portador de necessidades especiais”. Segundo a CP, o PPP dessa instituição escolar encontra-se em reestruturação e o tema da inclusão está recebendo um olhar especial, uma vez que a instituição recebe alunos que necessitam ser incluídos no processo educacional.

Nas palavras de Libanêo (2005, p. 345), “[...] o Projeto Político Pedagógico é um documento que propóe uma direção política e pedagógica para o trabalho escolar, 
formula metas, prevê açôes, institui procedimentos e instrumentos de ação”. Tratase de um documento com intencionalidade, que direciona as açóes inclusivas com vistas a atender as diferenças compreendendo o currículo, as atividades e o processo avaliativo dos alunos.

Quanto à questão da elaboração do currículo escolar, a CP disse: "[...] o currículo escolar é elaborado atendendo à legislação vigente”. Infelizmente nem sempre a legislação atende às especificidades dos alunos, situação essa, que acompanha os alunos que apresentam necessidades educacionais especiais. Carvalho (2004, p. 67) expóe que a escola precisa "[...] aprimorar suas ações para garantir a aprendizagem e a participação de todos, em busca de atender às necessidades de qualquer aprendiz, sem discriminaçôes".

Sobre o trabalho desenvolvido com a aluna, a CP explanou que "[...] acredita que o trabalho tem atendido suas necessidades, pois a aluna tem apresentado avanços significativos". As professoras comentaram sobre a inclusão de alunos com Síndrome de Down na escola regular: "Acredito que isso vem a contribuir muito com aprendizado e socializaçáo dos mesmos" (PR); "Foi um grande ganho, tanto para o aluno com Síndrome de Down, como para os demais, pois mostra a diversidade, a aluna aprende como respeitar o próximo com suas diferenças desde criança” (PI).

Diante do questionamento sobre a inclusão da aluna, se foi um avanço ou um retrocesso na reestruturação do sistema de ensino, assim opinaram: "Acredito que tudo tem seu lado positivo, e que precisamos trabalhar para que essas crianças consigam ter uma aprendizagem significativa" (PR). E ainda: "Foi um grande avanço, só que os professores ainda náo estáo totalmente preparados. O professor tem que sempre buscar melhores maneiras de ensinar e adaptar o ensino às diferenças. Hoje o sistema está se encaminhando para que as escolas estejam preparadas" (PI). Concordamos com Ribeiro (2003), ao mencionar que os sistemas de ensino náo estão preparados para trabalhar com a inclusáo e excluem os casos considerados mais complexos, eximindo a escola da pesquisa e da busca por formas mais apropriadas de trabalhar o processo de inclusão.

Indagadas se creem estar preparadas para assumir uma sala de aula com alunos com Síndrome de Down, as respostas foram: "Acredito que sim, porém tenho certeza de que tenho que me preparar mais, assim como já venho fazendo" (PR). E ainda: "Náo totalmente, pois acredito que o professor tem que sempre buscar maneiras de melhor ensinar seu aluno" (PI).

Ambas as professoras sustentaram que a relação com a aluna com SD é muito boa e que não houve nenhum problema de adaptação, pois ela já frequentava a educaçáo infantil. É muito carinhosa e age com respeito com todos da escola, interage com todos os colegas de sala e, na hora do recreio, as colegas a levam para brincar, segundo a PI. Com relação à aquisiçẫo significativa dos conteúdos, as professoras disseram: "Dentro de suas limitaçóes, sim" (PI); "Sim, olhando do começo do ano até hoje, vejo um grande avanço, mas exige muita dedicação e um tempo maior para que a aprendizagem aconteça” (PI). 
Sobre a alfabetização e as metodologias utilizadas com a aluna com SD: "A aluna com Síndrome de Down apresenta possibilidades de aprender. A aprendizagem da mesma é mais lenta, ela aprende dentro de suas limitaçôes, porém, ela conta com o apoio diário de uma itinerante, que a ajuda na execução das atividades e materiais de apoio, como alfabeto móvel e jogos" (PI). E ainda: "A aprendizagem da aluna não é da mesma forma, ela acaba demorando mais tempo para fixar os conteúdos que os demais alunos. É preciso atividades diferenciadas, com alfabeto móvel, material dourado, alguns jogos que a escola disponibiliza, sempre buscando algo que estimule o seu desenvolvimento" (PI).

Tal constatação novamente vem ao encontro do que é afirmado por Schwartzman (2007), no tocante ao fato de que crianças com Síndrome de Down possuem idade cronológica diferente da idade funcional. Não se pode, portanto, esperar uma resposta semelhante à daquelas que não têm a Síndrome nem alteraçóes de aprendizagem.

Ao indagar se recebem ajuda de outros profissionais no trabalho com a aluna com Síndrome de Down, a resposta foi positiva: "Sim, da coordenação pedagógica" (PR). E ainda: "Sim, eu e a PR procuramos trabalhar em conjunto, e a coordenadora sempre questiona sobre o desenvolvimento da aluna e se estamos precisando de algo" (PI). Apesar desse comentário, durante o período das nossas observaçôes não testemunhamos nenhum diálogo da professora com a itinerante em relação às dificuldades da aluna, atitude que faz uma grande diferença no desenvolvimento e no aprendizado das atividades na aula.

Quanto à indagação se o trabalho oferecido pela escola tem atendido às necessidades da aluna com a Síndrome de Down, as professoras narraram: "A escola vem oferecendo condiçóes, mas ainda não é o suficiente, necessita de mais materiais pedagógicos para manipulação, atividades com jogos e qualificação maior dos profissionais envolvidos com a inclusão" (PR). E ainda: "A inclusão é algo muito novo. A escola tem buscado alternativas para melhorar e atender suas necessidades. Gostaria que a escola melhorasse na parte dos materiais, pois a aluna gosta muito de jogos" (PI). O trabalho com alunos com necessidades educacionais especiais na escola regular é algo que podemos considerar como relativamente novo.

É em face desse cenário que precisamos ter em conta a reflexão de Santos (2007) sobre enxergar sinais, pistas, possibilidade de açôes, que talvez foram pensadas, mas ainda não instituídas. $\mathrm{Na}$ ação coletiva, podem emergir e nos apontar sinais e possibilidades da inclusão, superando o distanciamento entre o discurso da inclusão e a sua efetivação. É transparente a percepção de que incluir não é inserir alunos com necessidades especiais dentro de uma sala de aula, mas modificar-se e aprender a conviver com dificuldades e diferentes níveis de aprendizagem e fazer com que essa educaçáo inclusiva proporcione a esses alunos uma evoluçáo no seu desenvolvimento.

\section{Considerações finais}

Compreendemos, a partir deste estudo, que estão em curso mudanças e adaptaçốes na escola regular, em função do processo de inclusão. Tais mudanças deveriam ocorrer de forma mais acentuada, pois a maioria se verifica apenas nos discursos. As 
ações mantêm-se pendentes, o que dificulta o processo de inclusão nesse ambiente. A comunidade precisa reconhecer os fatores que influenciam o processo de inclusão e dar uma resposta a cada um deles, assegurando a educaçáa para todos, por meio de currículo apropriado, de modificaçóes organizacionais, de estratégias de ensino, de utilização de recursos e de parcerias específicas.

Devemos ter em mente que não é só função da escola, mas também da sociedade, desenvolver projetos e condiçóes para que a maioria dos alunos alcance sucesso na aprendizagem, independentemente das suas diferenças, quer físicas, culturais, sociais ou cognitivas. O princípio da escola inclusiva é que todas as crianças aprendam juntas, apesar das diferenças, ou seja, que todas tenham a mesma oportunidade de acesso, de permanência e de aproveitamento na escola, não obstante as características individuais peculiares. Para que isso se concretize, é fundamental que as crianças com deficiência tenham o apoio de que precisam, com as suas limitaçóes respeitadas e recebendo oportunidades adequadas. A intenção da inclusão não é igualar a criança aos colegas. É fazer com que a criança com Síndrome de Down aprenda tendo em vista as suas possibilidades.

As evidências levantadas nas observaçôes do cotidiano da aluna Down, comparadas aos relatos, sustentam a ideia de que o apoio oferecido pela escola é insuficiente para uma inclusão bem-sucedida. Esta pesquisa contribuiu para que ficasse evidente que o processo de inclusão escolar ainda está longe de acontecer, pois a escola ainda está se preparando para essa função. Devido à falta de uma proposta pedagógica, o que ocorre nas escolas públicas, até o momento, é a integração escolar, e não a tấo esperada inclusão.

Na perspectiva da inclusão o que se busca é uma prática pedagógica que atenda às especificidades e respeite a trajetória das aprendizagens dos alunos. Não basta aceitar as pessoas com necessidades especiais. A instituição escolar precisa de toda uma estrutura adaptada para atendê-las: precisa de professores capacitados; requer profissionais para apoio pedagógico, bem como estruturas física e pedagógica diferenciadas, para que verdadeiramente cumpra o seu papel social. A inclusão só se efetivará se medidas administrativas e pedagógicas forem tomadas pela equipe de gestão do sistema de ensino e da escola. O verdadeiro desafio consiste em modificarse e aprender a conviver com dificuldades e diferentes níveis de aprendizagem, a fim de fazer com que a educação inclusiva propicie aos estudantes um progresso no seu desenvolvimento pessoal e educacional.

\section{Referências}

ALVES-MAZZOTTI, A. J.; GEWANDSZNAJDER, F. O Método nas ciências naturais e sociais: pesquisa quantitativa e qualitativa. 2. ed. São Paulo: Pioneira, 1999.

BRASIL. Ministério da Justiça. Declaraçáo de Salamanca e linha de açáo sobre necessidades educativas especiais. Brasília, DF: Corde, 1994.

CARVALHO, R. E. Educação inclusiva: com os pingos nos “is”. Porto Alegre, RS: Mediação, 2004.

CHIZZOTTI, A. Pesquisa em Ciências Humanas e Sociais. 7.ed. São Paulo: Cortez Editora, 2005.

IMBERNÓN, F. (org.). A educaçáo no século XXI: os desafios do futuro imediato.Trad. Ernani Rosa. 2.ed. Porto Alegre: Artmed, 2000. 
LIBÂNEO, J. C.; OLIVEIRA, J. F.; TOSHI. Educação escolar: política, estrutura e organização. 2. ed. São Paulo: Cortez, 2005.

MANTOAN, M. T. E. Inclusão escolar: o que é? por quê? como fazer? São Paulo: Moderna, 2003.

MELERO, M. L. Aprendiendo a conocer a las personas com Síndrome de Down. Málaga: Aljibe, 1999.

RIBEIRO, M. L. S. Perspectivas da Escola Inclusiva: algumas reflexóes. São Paulo: Avercamp, 2003, p.41 - 51.

SANTOS, B. S. Renovar a teoria crítica e reinventar a emancipaçáo social. São Paulo: Boitempo, 2007.

SCHWARTZAN, J. S. Síndrome de Down. São Paulo: Memnon, 2007.

VIEIRA, F. D. PEREIRA, M. C. Se houvera quem me ensinará... "a educaçáo de pessoas com deficiência mental”. 2. ed. Lisboa: Fundação Calouste Gulbenkian. Serviço de Educação, 2003.

\section{Correspondência}

Anderléia Sotoriva Damke - Universidade Tecnológica Federal do Paraná - UTFPR Câmpus Santa Helena. Pr. Prolongamento da Rua Cerejeira, s/n. Bairro São Luiz - Santa Helena, Paraná. CEP: 85892-000 - Brasil.

E-mail:ana_paulaazevedo@hotmail.com - anderleiadamke@utfpr.edu.br

Recebido em 30 de abril de 2015

Aprovado em 10 de agosto de 2016 